\title{
On Locating Value in Making Moral Progress*
}

\author{
Toni Rønnow-Rasmussen ${ }^{1}$
}

Accepted: 13 June 2016 / Published online: 1 August 2016

(C) The Author(s) 2016. This article is published with open access at Springerlink.com

\begin{abstract}
The endeavour to locate value in moral progress faces various substantive as well as more formal challenges. This paper focuses on challenges of the latter kind. After some preliminaries, Section 3 introduces two general kinds of "evaluative moral progress-claims", and outlines a possible novel analysis of a (quasi) descriptive notion of moral progress. While Section 4 discusses certain logical features of betterness in light of recent work in value theory which are pertinent to the notion of moral progress, Sections 5 and 6 outline the ambiguous character of "making moral progress".
\end{abstract}

Keywords Moral progress · Value comparisons · Betterness · Value incomparability · Value dualism

\section{Introduction}

Locating value in moral progress turns out to be easier said than done. Basically, the location issue arises because claims to the effect that someone or something has (or has not) made moral progress are evaluative claims about certain kinds of changes. This is true at least about the ones that I am interested in here; they express (or at least entail) beliefs that so-and-so (i.e., a certain kind of change or history) is valuable. The location issue is, then, the problem of understanding to what part, if any, of this "so-and-so" value accrues. From formal axiology we know that value may in fact supervene on relations in more than one way. That this is true also of moral progress relations seems reasonable. The challenge facing anyone who wants to determine what changes merit being evaluated as examples of progress is first and foremost an evaluative challenge. However, on the way to doing so there are also a number of conceptual challenges. Henceforth I will be focusing on these, and so my aim here is not substantive (although I will refer to some substantive examples in order to illustrate some logical points). To begin with, however, I shall briefly address a metaethical issue. It plays no small role in

Toni Rønnow-Rasmussen

Toni.Ronnow-Rasmussen@fil.lu.se

1 Department of Philosophy, Lund University, Helgonavägen 3, 22100 Lund, Sweden 
many substantive discussions about whether or not moral progress is possible. The matter merits a comprehensive discussion, but to pursue it here would lead us far astray of the main objective of this paper. I will therefore confine myself to outlining the issue and to hinting at why I am setting this issue aside here.

\section{Moral Progress and a Metaethical Assumption}

Quite many things have been considered to be suitable makers of moral progress. Presumably, we give primacy to persons. It is our own and others' accomplishments or failures in this area that we are concerned about. However, in hindsight, different civilisations, eras, cultures, classes, nations, races, sexes, and much more have also been matched in terms of moral progress. To some people there is a bad ring to the notion of moral progress (and its logical siblings moral superiority, inferiority and decline). Most likely, the reason has to do with the fact that so many past and present views about moral progress obviously have been false, mistaken or ill-founded. They were simply ethical transgressions traceable to a tasteless pulp of racism, xenophobia and myopic love for one's own favoured culture, religion, ethical theory, values, nation, race, sex, gender and, not forgetting, love of oneself. Past and present bad examples of this muddy mixture should teach us to be cautious about what we describe as having made moral progress, but they are hardly a reason to place a ban on the notion of moral progress. Yet there are other reasons why people have been unwilling to make claims about moral progress.

En passant, by "moral progress claim" I shall henceforth have in mind claims to the effect that someone or something has made or has not made moral progress.

One reason, which is quite salient in many discussions about moral progress, concerns the idea that in order for there to be moral progress, moral realism has to be true. Unless there are moral facts or true (absolute) moral statements, there cannot be any moral progress. Interestingly, friends as well of foes of the possibility of making moral progress make use of this alleged relation between moral realism and moral progress.

Here is a quotation which exemplifies one of the approaches. It comes from the law scholar Richard Posner. After having suggested, as Posner puts it, that moral realism is "out" and moral relativism is "in" (Posner 1998), he goes on to claim:

My analysis also suggests that no useful meaning can be given to the expression "moral progress" and that no such progress can be demonstrated. (p. 1641)

In a later work (1999), Posner somewhat softens his denunciation:

Moral relativism implies that the expression "moral progress" must be used with great caution, because it is perspectival rather than objective; moral progress is in the eye of the beholder. (1999, p. 6)

The general point seems clear, though. Since moral realism is false, and moral relativism implies that moral progress is relative to the subject, we should be wary about using this notion. Of course, one philosopher's modus ponens is another philosopher's modus tollens, and so there is a common contraposition approach, which takes the form of a reductio ad absurdum. Here is how Emrys Westacott exemplifies the argument:

$[\mathrm{M}]$ oral relativism implies there is no such thing as moral progress [...] Almost everyone believes that moral progress can and does occur within a society. The abolition of 
slavery is a paradigm of such progress. So, any theory implying that such changes do not constitute progress must be false. By the same token, moral relativism can also be criticized for not allowing the possibility of moral decline, which also presumably occurs at times. ${ }^{1}$

Both sides greatly simplify matters, though. For one thing, there is more under the metaethical sun than moral realism and moral relativism. But for the purpose of this paper, there is actually no need to take a stand on whether the value we are referring to must be understood in accordance with a certain kind of metaethical position. Both realism, or more generally objectivism, and subjectivism (including relativism) can make sense in their own terms of the notion of "moral progress". Their disagreement will therefore fundamentally be of a metaethical nature. In what follows, I will not assume the correctness of any such metaethical claims. The examples (including their logical implications) which I will be discussing should be open to a number of metaethical analyses. ${ }^{2}$

\section{Intra- and Inter-Progress Comparisons}

In order to cut corners, I will introduce below an abridged way of a talking about the various claims that we make about moral progress. As we shall see, they basically fall into two categories.

Let us denote by $\mathrm{X}$ a world change or history, $\mathrm{H}$, that takes place between the period $\mathrm{t}_{0}$ and some later time, $\mathrm{t}_{1}$. It might be a grand change of history (e.g., classical antiquity) or it might be a very local, personal history. We can write this as say $X=\left[H, t_{0}, t_{1}\right]$. This allows us to present in a simple way different kinds of comparisons.

The first kind concerns what we might refer to as intra-comparisons. An example would be when I think that, in comparison with my teenager existence, I have (albeit not obviously) made some moral progress. Since the comparison concerns different stages of one and the same person, we might refer to it as intrapersonal comparison. We can express this by letting X denote the history between, say, my eighteenth birthday and my present state. We might then compare $\mathrm{X}$ to a point (rather than a period) in time - my eighteenth birthday — which we can understand as a change $Y$ that has not taken place; we can suitably express this as $Y=\left[H, t_{0}, t_{0}\right]$. This kind of intramoral-progress relation can then be expressed in a simplified way, by saying that $\mathrm{p}$ in $\mathrm{X}$ has made moral progress in comparison to $\mathrm{p}$ in Y. Let us write this as follows:

$$
\text { Intra-comparison : }(\mathrm{p}, \mathrm{X})>(\mathrm{p}, \mathrm{Y}) \text {. }
$$

For the time being, we can read the arrowhead above as "having made moral progress in comparison with". Meanwhile, I want also to give two examples of inter- rather than intracomparisons. An inter-comparison, i.e., a comparison between two different entities, might concern the same simultaneous periods. We might say for instance that in comparison to North Korea, Sweden has witnessed an unparalleled moral progress the last forty years. Or we might say that North Korea has made more moral progress in one year than what Sweden has done in

\footnotetext{
${ }^{1}$ Quoted from Westacott (2015).

${ }^{2}$ Needless to say, both objectivism and subjectivism face serious problems (see e.g., Rønnow-Rasmussen 2003 , 2011). For a recent illuminating account of subjectivist positions in terms of value constitution, see Fritz-Anton Fritzon (2014).
} 
100 years. I wouldn't necessarily endorse either of these claims, but they are not nonsensical. In fact, there are a number of different kinds of intermoral-progress comparisons. However, I believe the two more common kinds are the following one- where $Y$ refers to $\left[\mathrm{H}^{\prime}, \mathrm{t}_{0}, \mathrm{t}_{1}{ }_{1}\right]$ :

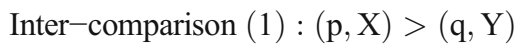

p's change in X has been valued higher than q's change during another history. But, of course, we might also see how $\mathrm{p}$ and q fare in the same world. Thus,

$$
\text { Inter-comparison }(2):(p, X)>(q, X)
$$

is short for ' $\mathrm{p}$ in $\mathrm{x}$, in comparison with $\mathrm{q}$ in $\mathrm{x}$, has made moral progress'.

The inter-comparison claims concerning moral progress might seem less interesting than (some kinds of) intra-comparison claims (at least in the sense that derivative claims appear less interesting than non-derivative claims). However, since inter-comparison claims are not uncommon (and also because I fear we will witness many more bad examples of such claims in the future), I will also in a while discuss these in some detail.

Any analysis of moral progress must eventually specify what it has in mind with "moral". Unfortunately, I do not have anything novel to say about this vexed issue, and so I shall not try to specify its content. There are other thorny issues circling around the notion of moral progress, and so my focus here lies elsewhere. ${ }^{3}$

As to progress, it is not just any change or passing successively from one period to another that constitutes progress; it is a change to the better. ${ }^{4}$ The reverse implication does not hold, though. Not all betterness relations are progress relations. That too seems clear. (For instance, I might think that one computer is better than another, just because it is cheaper, although I know that otherwise the two computers are exactly similar.) Not even all changes to the better are example of progress. When my favourite team scores it is a change to the better, but not necessarily an example of progress-making. So making progress is not mere valuable change; there is a logicality to progress, i.e., there is some (single or complex) property that a valuable change conceptually must have in order to qualify as progress. ${ }^{5}$

\footnotetext{
${ }^{3}$ An anonymous referee wondered whether what I have to say about moral progress, then, generalizes to other kinds of progress, such as for instance aesthetical progress. I believe it does generalize. However, to argue that the points made in this paper about moral progress also generally apply to at least some other kinds of progress would require a detailed argument (which would in part depend on some substantive views about what are examples of different kinds of progress). However, there are also important differences. To display these, it would be necessary, I think, to compare the supervenience base of the moral betterness relation (i.e., that in virtue of which something is a moral betterness relation) to the base on which e.g., the aesthetic betterness relation supervenes; eventually this should enable us to determine what is characteristic of moral rather than aesthetic progress.

${ }^{4}$ Dale Jamieson raised the interesting issue (personal communication) of whether moral progress might involve values other than "betterness". The answer is yes, I think, but it should come with an important qualification. With one general exception, all of the values that I can think of (e.g., that $\mathrm{x}$ at $\mathrm{t}_{1}$ displays kindness or perfection or skill to a higher degree than $\mathrm{x}$ at $\mathrm{t}_{0}$ ) are such that they are ultimately best understood as species of goodness. And so, generally speaking, any progress relation will be describable in terms of betterness. The possible exception I have in mind concerns the possibility of radical value dualism. Suppose what is good, period and what is goodfor cannot fully be understood in terms of each other; in that case, progress relations might not only be expressible in terms of goodness (and hence betterness relations) but also in terms of goodness-for (and accordingly, in terms of betterness-for relations). However, in what follows, I will set this issue aside. For more on this, see Rønnow-Rasmussen (2013) and Rabinowicz and Rønnow-Rasmussen (2015).

${ }^{5}$ A common view (see e.g., Godlovitch 1998) depicts progress as valuable change that displays some kind of purposiveness, or more generally, as being teleological in nature. Later on, in Section 6, I shall suggest how a change might display a kind of purposiveness. By the way, that a change displays purposiveness is here understood as being consistent with the fact the change did not necessarily occur.
} 
A caveat is in place. There might be a non-evaluative notion of progress, i.e., one such that we could agree about what is progress without endorsing (or being logically committed to) some value (some betterness-) judgement about the particular change of history that is considered to ground the progress. I do not want to exclude the possibility of such a purely descriptive notion. For instance, on my way to work, I noticed that workers had finished the first floor of a building under construction. It would seem quite natural were I to have said that in this case some progress had been made. But must we next conclude that I actually find something valuable about this building site? Suppose I didn't. Would I make sense if I in this case said that the construction workers had made progress? Wouldn't it be more accurate to say that I had witnessed a change or something to that effect? Not necessarily. One might argue that if we do believe there is nothing in a minimal sense positive about a certain change, we could still make sense of a "progress claim" that would be (quasi) descriptive rather than evaluative. There are at least two possibilities, one of which is often overlooked. The first suggests that we are not really making a genuine moral progress claim; the second involves a peculiar kind of belief.

As to the first suggestion, we might have in mind with "progress" a change that takes someone or something closer to the satisfaction of some goal or end that we think is valued by someone. So although we do not value the goal or end, the fact that we recognize that there is such a goal or an end that is thought of as good by someone, $\mathrm{x}$, is enough for us to describe the change as constituting "progress-relative-x's" (evaluative) perspective. This is not an evaluative claim, at least not in the sense in which it would commit you to believing that something is valuable. ${ }^{6}$ Nonetheless, on pain of circularity, its analysis eventually requires a full-fledged evaluative use of "progress".

To understand the alternative, let $\mathrm{E}$ refer to an end for which a certain change, $\mathrm{x}$, is expected to increase the probability of its realization: This approach, then, treats " $\mathrm{x}$ has made moral progress" as expressing the belief that " $\mathrm{x}$ has undergone a valuable change towards the realization of $\mathrm{E}$ on condition that $\mathrm{E}$ is valuable". Here we express a categorical (and not a conditional) belief (or at least a cognitive attitude), albeit a peculiar kind - what we may refer to as a "belief on condition". Although the latter does not commit us to idea that something is in effect valuable ${ }^{7}$ - it too is dependent on an analysis of "value". However, this latter suggestion is not, as the first kind, an example of an "inverted commas use", and as such it is perhaps preferable.

Other examples of "descriptive" uses of "progress" will be harder to keep apart from what in my view would be more appropriately described as mere change or succession which are descriptive notions; progress is typically not - at least not the kind of progress that I find interesting and which I believe over the years has steered up moral philosophers. This use of "moral progress" is an evaluative one, i.e., one that is best depicted as expressing a kind of betterness-relation. ${ }^{8}$

\footnotetext{
${ }^{6} \mathrm{Cf}$. "in case of emergency press the button" with "press the button". While the latter is a full-fledged imperative, the former is not. Or compare "when or if the alarm sounds, people will start running" with "people will start running". While the latter commits you to the existence (albeit in the future) of running people, the former does not.

${ }^{7}$ As I discuss elsewhere in "On-Conditionalism-On the Verge of a New Metaethical Theory" (work in progress), this pattern of "on condition" analysis is also open to an evaluative understanding of value terms in general, which makes it into an interesting but nonetheless ignored metaethical alternative.

${ }^{8}$ Macklin has suggested that "moral progress judgements" are not only evaluative; they are moral judgments: "[...] it should be clear that the term 'moral progress' is an evaluative notion. That is, judgments of the form ' $x$ is more morally progressed than y' always express a moral judgement” (Macklin 1977, p. 371). However, just why she describes them as moral judgements is not clear to me. In fact, later on in her very interesting paper, she qualifies her claim: "The concept of moral progress appears to be a sort of metamoral concept [...] enabling us to evaluate theoretical entities, such as ethical theories, as well as to assess their application in cultural artefacts such as laws, customs, social institutions, and public debate or outrage over moral issues" (ibid., p. 380).
} 


\section{Expanding the Logical Space of Moral Progress}

If moral progress claims express betterness comparisons, we should next turn our attention to this kind of value. Now, it might seem that when we evaluate different stages of $\mathrm{p}$ (or $\mathrm{p}$ and $\mathrm{q}$ ) in terms of moral progress, the logical space of our comparisons will be exhausted by the trichotomy "is better than", "is worse than" and "is equally good". To these three we should perhaps add incomparability or incommensurability. If two entities, $\mathrm{p}$ and $\mathrm{q}$, are such that none of the three relations hold between $\mathrm{p}$ and $\mathrm{q}$, there is at least some reason to think that $\mathrm{p}$ and $\mathrm{q}$ are in fact incomparable in terms of moral progress. Some objects might be such that we cannot compare them in terms of moral progress. Perhaps this is so. However, it is not obviously so. Notice, by the way, that we might agree that two values or value-bearers are incommensurable, in the sense that we cannot represent these values by a cardinal unit of measure, say, dollars or preference strength. We could still think that they are comparable. As Ruth Chang has argued, incommensurability should not be confused with incomparability. ${ }^{9}$ She is also a stout defender of the idea that we should add yet another kind of relation to the three mentioned above.

According to Chang, and she is not alone in this, we need to recognize that things can be on a par. So although it is not true that $\mathrm{p}$ is better or worse than or even equally as good as q, they might nonetheless be comparable in the sense that they are on a par. Chang thinks, for instance, that what has become known as the small improvement argument actually supports this idea of a fourth relation. Interestingly, the argument was actually intended to show that things may be incomparable. ${ }^{10}$ Chang thinks it shows that there are items that are not related to each other by one of the standard three relations. If they still are comparable, they must be comparable by means of some fourth relation (parity). Chang also supplies such an argument (see her Unidimensional Chaining argument in sec. 2 of Chang 2002). ${ }^{11}$

The small improvement argument sets out from the idea that two items $\mathrm{p}$ and $\mathrm{q}$ might be neither better nor worse with respect to some value. In some respects relevant to the value in question, $\mathrm{p}$ is better, in other respects, it is $\mathrm{q}$ which is the better, but no one is better, period. Applied to our discussion, we can imagine the following case: Eve, who in recent years has become an unprejudiced person, might not be better or worse with respect to having made moral progress than Charlie, who during the same period has become a very compassionate person. But suppose we also imagine a slightly improved Eve. This Eve+, as we can call her, has become just a touch less prejudiced than Eve. Would this mean that we now have to say that Eve + is better than Charlie with respect to having made moral progress? Chang might well be right in that it can be rational to resist the conclusion that Eve has now, in the shape of Eve+, made moral progress vis-à-vis Charlie. But in that case, we must conclude that Charlie and the original Eve cannot be equally as good with respect to moral progress. This seems clear, since if Charlie and Eve were equally as good, then a small improvement of Eve would make her better than Charlie. To this we can then add that if Eve and Charlie are in fact comparable with

\footnotetext{
${ }^{9}$ I agree with Chang that if we understand incommensurability in this way, two incommensurable objects might nonetheless be comparable with each other. However, as I suggest further on, it is not clear that all kinds of incommensurability must be understood in this way.

${ }^{10}$ Cf. Gustafsson and Espinoza (2010).

${ }^{11}$ This argument has been much discussed. For a recent treatment, see Henrik Andersson (2016).
} 
respect to having made moral progress, then, if they are comparable, ${ }^{12}$ they seem to be rather roughly equal, or, as Chang puts it, on a par. ${ }^{13}$

Chang has also argued for another idea that is of interest in this context. She believes that all comparisons are in fact relativized to what she refers as a covering value. If she is right about this, then the logical form of a comparison, for instance, in terms of better than, will be the tripartite expression: " $p$ is better than q with respect to a covering value V", where V might be excellence or happiness, or even (I assume) moral progress. If she is right about this, it should in principle be possible to come up with such a covering value in all comparison cases, and so we have an additional argument that there are in principle no cases of incomparability at all (at least not ones that cannot be ruled out on formal grounds). ${ }^{14}$

Chang's idea makes much sense. Still, I cannot help thinking there is unfinished business that needs attention. It seems at least as if an irreconcilable value perspective might create a kind of incomparability. This would be the case when the choice between the perspectives cannot be made in terms of some more basic value perspective.

For instance, consider the following scenario: If you spend all of your salary on an expensive hobby of yours, it will be good for you. Call this option A. But you might instead send some of your money to charity; this would be a good thing to do, although not necessarily good for you. Call this B. Now, suppose you are not sure what to do, and you cannot do both. So you would like to be able to not merely haphazardly have to decide between A and B; you would like to settle this issue in an unbiased way by comparing them to each other. By "unbiased", I mean that you don't want to settle in advance which of the two options (A or B) should be ruled out.

Chang is right, I think, that we can compare A and B; we can for instance say that B is better than A with respect to your making moral progress. ${ }^{15}$ But, then again, A is better than B with respect to your enjoyment. The first comparison seems to be one with respect to something that is good, period, namely making moral progress, while the latter is done in terms of giving you pleasure, i.e., something that is good-for you. But if you want to compare these options in an unbiased way precisely because you cannot make up your mind about whether to realize what is good or what is good-for you, it is not clear how you should proceed. Whatever covering value you introduce here will exemplify either one of three possible values: either it will be a good, period or something that is good-for you or it will be a complex consisting of something that is both good, period and good for you. As to the two former possibilities, they seem not to be consistent with an unbiased comparison. So although A and B certainly in one sense are comparable, given the premises I am discussing here, it is not quite clear that A and B are in fact comparable in all cases; the comparison will in some

\footnotetext{
${ }^{12}$ It should be stressed that the small improvement argument does not assume comparability. So to go from "Eve and Charlie are not equally as good with respect to moral progress" to "Eve and Charlie are on a par", Chang needs her Unidimensional Chaining argument (and to exclude vagueness).

${ }^{13}$ See Wlodek Rabinowicz (2008) who shows that the traditional trichotomy of preference relations can account for all four value relations (i.e., 'better than', 'worse than', 'equally as good', and 'parity').

${ }^{14}$ On the other hand, it might also be the case, as Wlodek Rabinowicz rightly suggested (personal communication) that we instead get a possibility of lots of incomparabilities with respect to various covering values. It should be possible to find some $\mathrm{V}$ with respect to which $\mathrm{x}$ and $\mathrm{y}$ are comparable. But it should also be possible, one might think, to find some other $\mathrm{V}$ with respect to which $\mathrm{x}$ and $\mathrm{y}$ are incomparable. More about this below. ${ }^{15}$ Chang's notion of "covering value" is not entirely clear to me, though. Chang says that "Every comparison must proceed in terms of a value" (Chang 1997, p. 5). However, she immediately makes clear that by "value" or "covering value" she has in mind "any consideration with respect to which a meaningful evaluative comparison can be made" (loc.cit.). I am not quite sure why she identifies values with considerations.
} 
cases be biased and so in those cases it cannot be represented in an unbiased way. And if that is the case, we are not in the position to make the kind of comparison that we set out to do. This suggests that, just as we might want to say that $\mathrm{x}$ and $\mathrm{y}$ are incommensurable in the sense that we cannot represent these values by a cardinal unit of measure, there is another sense of incommensurable in which we cannot represent these values by an unbiased covering value (i.e., a value that does not bias the comparison). ${ }^{16}$

What does this, then, say about whether and to what extent entities might be incomparable in terms of being conducive to or constitutive of moral progress-making? Is $\mathrm{x}$, which is good for me, comparable to $y$ that is good, period - given that the covering value is moral progress understood as being good, period? We might at least tentatively conclude that for radical value dualists, there seem to be cases in which making moral progress must be based on a decision rather than on an unbiased comparison.

Chang is aware of the complication of a radical value dualism (Chang 2015, p. 211; cf., Chang 2002, 78 ff). But she believes it is not an issue of incomparability or incommensurability but rather one about the "normative irreducibility" of good and good-for. She might be right, and so our possible differences may in the end turn out to be of a purely verbal nature, but, then again, they might not. It is indeed to a large extent an issue of normative irreducibility, but normative irreducibility can be seen as precisely what gives rise to a different kind of incommensurability (or incomparability) than the one she has in mind. This might occur when we want personal and impersonal value perspectives, and we do not have access to a more basic value perspective. Again, if it is indeed a verbal matter, the lesson is that there is more to the assessment of value relations than (in)comparability and (in)commensurability (in Chang's sense). ${ }^{17}$

\section{Two Kinds of Betterness}

Yet more facets to moral progress need to be addressed next; they too concern betterness. This kind of (dyadic) value admits of a qualitative as well as a quantitative reading. For example, two persons, $\mathrm{x}$ and $\mathrm{y}$, might both have been subjected to the same amount of psychological changes, but x's amount qualifies as qualitatively better, and is therefore assessed in more positive terms. The reverse case also seems possible; x's changes might be much less important than the changes which have affected $\mathrm{y}$ but $\mathrm{x}$ has been affected by a much greater number of changes. Moral progress accordingly admits of a quantitative as well as of a qualitative understanding. One might try arguing that only one of these relations constitutes genuine progress-making. However, in my view, it would be hard to make a convincing case for either one as the only way to understand moral progress.

\footnotetext{
${ }^{16}$ As to the third possibility, suppose we compare what is good, period with what is good-for you in terms of importance. Now, importance might be an example of both value, period and value-for, and as such it seems as if we could make a comparisons after all. For one thing, it is not given, as Wlodek Rabinowicz has pointed out (personal communication), that what is good for you is more important for you than what is good. It might be less important for you. E.g., it is good to help people who needs to be helped, but sometimes doing so will be detrimental to what is good for you. In some people this insight does not prevent them from pursuing what they express as being important, namely to do good. Another possibility would be to make the comparison in terms of what is worthy of your promotion. Rabinowicz rightly pointed out that it is not clear that what is good for you is more worthy of your promotion than what is good. Nor is it clear that it is less worthy.

${ }^{17}$ For a discussion of some serious difficulties surrounding the notion of parity, see Schoenfield (2014).
} 
There is a related but still different matter that must not be confused with the above issue. It concerns what we might refer to as the Ortega-Newton dispute discussed mainly among scientists and philosophers of science. In sum, Newton's aphorism (in his letter to Robert Hooke, 15 Feb. 1676) that he had been able "to see further only by standing on the shoulders of giants," 18 is taken to express (or as at least support) the idea that science advances due to the work of geniuses. This view is then contrasted with Ortega y Gasset's idea that science proceeds only because of the work by a mass of mediocre researchers. ${ }^{19}$ In light of this, an analogous question might arise concerning what makes something progress morally. Again, I see no reason why there cannot be both kinds of moral progress - one made by moral giants and another made by the rest of us.

These substantive issues apart, I shall take the arrowhead in the intramoral- as well as the intermoral-progress cases to be expressions of an asymmetric relation. This seems safe to say about progress whether or not it is moral progress. Arguably, this is also true when it comes to inter-comparisons, and not only for intra-comparisons. For example, that $\mathrm{p}$ in $\mathrm{X}$ has made moral progress in comparison with $\mathrm{q}$ in $\mathrm{X}$ entails the falsity of ( $\mathrm{q}$ in $\mathrm{X}$ ) having made moral progress in comparison with $\mathrm{p}$ in $\mathrm{X}$.

One might wonder whether it also entails the truth of $\mathrm{p}$ being morally superior to $\mathrm{q}$ ? Or that $q$ has to be morally inferior to $\mathrm{p}$ ? If $\mathrm{p}$ has made moral progress in $\mathrm{X}$ compared with what $\mathrm{y}$ has made in $\mathrm{X}$, is it the case that $\mathrm{q}$ is morally inferior or $\mathrm{p}$ is morally superior?

As long as we keep in mind that the questions concern inter-comparisons, logically it does not seem to follow that if $\mathrm{p}$ has made moral progress in comparison with $\mathrm{q}$, then $\mathrm{p}$ is also morally superior in comparison to $q$. If we say that $\mathrm{p}$ has made a change to the better relative to $\mathrm{q}$, it might still be the case that $\mathrm{q}$ is morally superior to $\mathrm{p}$; whether or not it is superior entirely depends on the level of progress made by $p$ and $q$ when the change began. That $q$ at $t_{0}$ has made much more moral progress relative to $\mathrm{p}$ at $\mathrm{t}_{0}$, is perfectly compatible with $\mathrm{p}$ having made moral progress in comparison with $\mathrm{q}$ at some other period of time.

Here is a complication that inter-comparisons might give rise to. Suppose $\mathrm{q}$ in $\mathrm{X}$ morally declines with respect to how q was originally. If $\mathrm{p}$, during the same period, has not changed in any substantial way, should we then conclude that $\mathrm{p}$ has made moral progress with respect to $\mathrm{q}$ in X? Perhaps this would be to stretch the notion of making progress a bit too much. We must therefore either introduce some sort of requirement that would rule out this possibility —or at least be aware that our inter-comparison claims are in fact always in a sense relativized claims and as such they do not say anything about the intra-comparison level of moral progress made by any of the compared objects.

So What about Intra-Comparisons?

Interestingly, there is a difference between the two kinds of comparisons. Suppose I have made moral progress in comparison with who I was as, say, a teenager. It seems to follow that I am then morally superior vis-à-vis my teenager existence. In fact, this does follow on condition that we do not have a pro-tanto sense of moral progress in mind. It would not be true, e.g., if I have made progress in one respect but otherwise have declined.

\footnotetext{
${ }^{18}$ Quoted in R K Merton (1965).

19 Ortega y Gasset (1932).
} 
It should be clear, then, that $(\mathrm{p}, \mathrm{X})>(\mathrm{q}, \mathrm{X})$ is consistent with the fact that $\mathrm{q}$ has made some moral progress; what the relation states is that $\mathrm{p}$ has made progress relative to $\mathrm{q}$, and so if $\mathrm{q}$ has morally progressed relative to something else, $p$ has done so to a higher degree. ${ }^{20}$

These platitudes barely scratch the surface, however. ${ }^{21}$ But things get more interesting.

\section{Two Kinds of Making}

Suppose someone said that the Netherlands has made more moral progress than North Korea. Compare this to someone who claims that, say, a certain person, Maarten, has made moral progress in comparison with how Maarten was twenty years ago, or that the average Dutch person today has made moral progress in comparison with the average Dutch person 100 years ago. We might believe that if we analyse the first kind of claim, the one about countries, it is bound to boil down to a claim like the latter one, i.e., a claim about the progress made by certain persons or persons in general. One might believe this to be true or at least believe something a bit less compelling to be true, namely that any claim to the effect that something has made moral progress is either a claim about some being having made or experienced something or a claim that eventually derives in some way from a claim about some being having made or experienced something. ${ }^{22}$ In fact, as we proceed, I will show there is reason to doubt even this latter more cautious claim. No person (or being), that is, need to have made moral progress in order for moral progress to have been made. In fact, just what we have in mind with "made" in the expression " $x$ has made moral progress" will make a difference for what substantive views we take about what can and cannot make moral progress. As should become clear, "moral progress" is in effect an ambiguous expression.

Consider Maarten again. It has been suggested to me, by Dan Egonsson (personal communication), that in order to have made moral progress, a person must somehow have been actively involved in this change; it is not enough that the change merely happens to him. One challenge to this sort of view is, of course, to specify just what we mean by "actively involved". But suppose we did manage to specify an acceptable view on this vexed matter. In that case, this "agency-requirement", as we might call it, is applicable to the kind of moral progress made by agents, but prima facie it would hardly apply to all kinds of progress makers. Some of the entities people have compared to each other in terms of progress are not agents in any ordinary sense of this term, and so they cannot satisfy the agency-requirement. It seems therefore as if we can talk about moral progress in at least two ways. This need not be a cause

\footnotetext{
${ }^{20}$ What should we say about a case in which $\mathrm{p}$ has declined at $\mathrm{t}_{1}$ but is back to square one at $\mathrm{t}_{2}$ ? We should say, I suppose, that $\mathrm{p}$ has made moral progress vis-à-vis $\mathrm{p}$ at $\mathrm{t}_{1}$ but not vis-à-vis $\mathrm{p}$ at $\mathrm{t}_{0}$.

${ }^{21}$ The above entailments will not always hold. It is at least imaginable that someone might compare $\mathrm{p}$ to $\mathrm{q}$ in terms of qualitative features, and then go on to compare $q$ to $p$ in terms of quantitative features. Or we might think $\mathrm{p}$ has made progress in terms of e.g., no longer being overly aggressive while $q$ has made progress in overcoming some irrational recalcitrant emotions, say, an irrational fear of strangers. Such pro tanto comparisons of moral progress might then lead to some confusion if someone else has an all-things-considered sense or some other protanto sense in mind. Again, in theory this ought not to be problematic once we are clear about the differences, although I suspect that confusing these two senses often explains why people disagree about the truth of moral progress claims. Whether we have pro-tanto or all-things-considered comparisons in mind, it must be possible to specify that in terms of which we make the comparison.

${ }^{22}$ Why "being" rather than "person" or "agent"? Since it is not clear to what extent our distant ancestors were persons, and since it seems clear that we should be able to say that in comparison to who we have evolved from, we have made moral progress, it seems better to be neutral on this matter. In this way, we have not excluded other species by definition from being capable of moral progress.
} 
of distress if the two senses cannot be applied to one and the same object, say persons. Unfortunately, I shall argue that people are in fact open to both these senses.

Let us consider some other possibilities. Suppose someone is born with a mutation making him in an unparalleled way sensitive to other people's suffering. Or suppose someone, unknowingly to another person Geert, has tinkered with Geert's brain to the effect that he now sincerely renounces his racist views and actions from the past. ${ }^{23}$ Suppose we also think that these are valuable changes. Should we in addition believe that these two persons then have made moral progress? Since they are hardly actively involved in the changes, the answer seems to be no. That is, not if the only way a person can make moral progress is to meet the agency-requirement. But, in fact, showing that there is yet a sense in which people can make moral progress is fairly straightforward.

In one sense, we might believe that e.g., Geert has not sufficiently been involved in the change to the better, and for that reason he has not made any moral progress. On the other hand, we might want to say that Geert's change made the world better in some sense, and that this is enough to say that at least the world has morally progressed. I am inclined, albeit for reasons of a purely intuitive nature, to say the latter. I am leaning towards it in part because I consider the change to be valuable, but also in part because I take it as involving a correction of some sort - we move from one state of affairs in which someone considered racist acts to be correct or appropriate or fitting or of no negative value at all to a state of affairs in which such acting is assessed as being incorrect or inappropriate behaviour. This shift might then be regarded as not merely a valuable change but as displaying minimally that which something conceptually must satisfy in order to be an example of a moral progress, i.e., given that correcting or putting things right might be viewed as a minimal kind of making progress while the opposite suggests a decline. ${ }^{24}$

Of course, whether this is an example of how we might account for the teleological character of progress is certainly contestable. However, I would like to stress that my main reason for giving voice to this speculation here is actually that it just might illustrate one interesting aspect. Thus, the shift from falsity to truth or from inappropriate to appropriate acting illustrates, I think, that the location of value in making moral progress need not always or exclusively be limited to that which the change leads to; it is not always that the value involved in moral progress is to be identified with the value of the end relatum. The value might in fact accrue to the very relation. So although a change might in effect be an unimportant change to the better, the fact that it was a change from, say, a state of affairs containing false claims to a state of affairs containing true claims, is in fact not a mere change to something valuable, it is a way in which the world may have made some progress in virtue of the nature of this change. But the curious thing is that if we are indeed inclined to say that what happened to Geert contributed to making the world better, and that the world therefore in this case has morally progressed ceteris paribus, it is obviously because we are ready to apply a notion of moral progress that seems less demanding than the one involving the agency-

\footnotetext{
$\overline{23}$ Studies show that manipulating the neurotransmitter serotonin in persons has an effect on attitudes, behaviour and even ethical decision-making in a laboratory setting. The example might therefore not be too far-fetched, I think. See e.g., Crockett et al. (2010).

${ }^{24} \mathrm{I}$ am inclined to say that in this case the change to the better is not an example of mere change to the better; it is progress of some kind. Why? If you see racism as a sort of error, you can perceive correcting the error as a sort of progress and not merely as a valuable change. Also, going from what is correct to what is incorrect is not a mere negative change; it is a decline.
} 
requirement. The world is not actively doing anything. But if $\mathrm{I}$ am ready to use this attenuated sense of moral progress about the world, what logically or even substantively prevents me in the first place from applying it to Geert? As far as I can see, nothing. One might question, of course, the examples of substantive moral progress claims that I used-after all, I did not argue for them here. Still, it seems easy to imagine a person who has undergone some valuable changes (say, in terms of acquiring a wider scope of morally relevant emotions and attitudes) because of favourable circumstances out of his control. Such a person might then qualify as having made moral progress in this latter sense in which the world has made moral progress. This, then, suggests that moral progress applied to persons is in fact an ambiguous expression. ${ }^{25}$

Before I introduce another ambiguity, I would like to briefly comment on yet a possible objection to what I have said so far. One might object that I am incorrectly assuming that states of affairs (or more accurately, obtaining states of affairs, which is what I take facts to be), worlds and relations can be valuable in some interesting sense, and that my account therefore is not quite as metaethically neutral as I suggested at the outset. Following Geach (1956), one could claim that such entities cannot be bearers of value. Geach argued that the apparent predicative uses, of the form " $a$ is good", are incomplete expressions that need to be filled out with a specification of the appropriate object category to which $a$ is supposed to belong and within which it is taken to be an exemplary specimen. But since he thought it did not make sense to talk about an exemplary specimen of (the object category of) states of affairs, he maintained that we cannot regard the expression "that $p$ is the case is good" as elliptical for "that $p$ is the case is a good state of affairs. Geach's attack on the predicative use of 'good', albeit influential, is nonetheless controversial among value theorists (see. e.g. Pigden 1990; Zimmerman M 2001). In fact, it seems quite natural to turn the tables on a Geachan who, due to his all-embracing attributivism about "good", excludes facts as not being valuable; i.e., one might counter and argue that it is rather a Geachan approach that faces a challenge if this view on purely metaethical grounds is incompatible with facts being valuable. I am also not quite sure just how metaethical neutral Geach's position is. Be that as it may, there are different things to be metaethical neutral about. So although I think that what I say here about moral progress should be open to cognitivist and noncognitivist alike, I am here biased towards value bearer pluralism that might well be inconsistent with at least a version of Geach's view that excludes facts from being bearers of value. But I do not see why a "predicativist" might not agree with an attenuated version of attributivism which says for instance "that $\mathrm{p}$ is the case is good" is elliptical for for the attributive statement "that $p$ is the case is a good state of affairs". Whether there are such good state of affairs would then be a matter of substantive reasoning (cf. Rabinowicz and Rønnow-Rasmussen 2016). ${ }^{26}$

Turning next to the ambiguity that I referred to above, I need to first say something about the domain of moral progress discourse; we need, that is, to say something about the very features or properties of $\mathrm{p}$ and $\mathrm{q}$ that we are comparing in terms of progress. As we shall see, such features may be valuable in different ways.

\footnotetext{
$\overline{25}$ A caveat: although we might want to say that Geert has made moral progress, this is consistent with arguing that our species has not made any moral progress. See Sartwell (2015), who doubts that we are any morally better than our ancestors.

${ }^{26}$ I thank an anonymous referee for forcing me to confront this issue more explicitly.
} 


\section{The backward- and forward-Looking Senses}

Suppose we say that country A has made more moral progress than country B just because the legal system in A differs from the legal system in B, whether or not people comply with the law or the law works in practice. In that case, there is reason to believe that we are employing the backward-looking sense of 'moral progress'; it disregards any accomplishing features, i.e., value-making features we expect will be accomplished by the change and instead focuses on other kinds of progress-making features (i.e., features the value of which make the change into a change to the better). ${ }^{27}$ The difference might be subtle, but it is responsible for some confusion, or so I believe. There is also a perspective that is central to what we might accordingly call the forward-looking sense of moral progress. In short, while the backward sense turns on the value of the progress-making feature, the forward-looking sense turns on the instrumental value of what the progress-making feature promotes or at least on what a change promotes.

Here is an example of a backward-looking sense - one, moreover, that helps to illustrate the point from Section 5 about moral progress being made despite there being no person who has made moral progress: In 1934 Sweden enacted a eugenic legislation that was only formally abolished in 1976. An estimated 21,000 persons (sic) were forcibly sterilized during this period - a majority of whom were women. Many who suffered this treatment by the Swedish state did so because they were Roma women. It seems quite clear that Sweden, in at least one respect, made moral progress in 1976. I do not doubt that this was in part due to the fact that some people had made moral progress. However, I might nonetheless be wrong about this, but whether or not the people who enacted the law actually had made any moral progress, it would still make sense to say that Sweden, by giving up it eugenic legislation, made a valuable change to the better. ${ }^{28}$

One might question the scope of the backward sense. It could be argued that although the backward sense might be applicable to certain kinds of progress-makers it does not apply to persons. Persons cannot have made moral progress unless what they have changed into has some positive effect on the moral behaviour of the person. This objection would certainly need some unravelling. Unfortunately, this will have to wait. However, there might be some truth to this claim. But, and I think this is important to bear in mind, although someone might or might not make moral progress qua moral agent, it is still possible to make moral progress qua agent. The latter seems essential for the evolution of moral agents from agents. That is, debatably, a moral agent needs to be employing moral judgments or concepts, and so it might be argued that such an agent will only make moral progress qua moral agent if his moral reasoning has become better in some sense. But even if we agreed to this, it does not follow that a non-moral agent, i.e., an agent who does not reason morally cannot make progress in terms of having from a moral point of view, a better set of dispositions, motives, or attitudes. In fact, acquiring the ability to reason morally might be such a "progress-making" improvement.

Suppose we agree that agents - whether or not they are moral agents - can make moral progress. In that case, we should be able to argue for applying the backward sense to a wide variety of entities - even those that do not have in any plausible sense moral reasoning capacities. There are different ways to do so. But to illustrate this point, it might be a good

\footnotetext{
${ }^{27}$ Its roots go to the distinction (in value theory) between two kinds of value which a feature may possess; the feature itself might be valuable or it might be valuable for what it promotes.

${ }^{28}$ See the White Paper from the Swedish state (2014:8).
} 
idea to draw on the resources from virtue ethics. Virtue ethicists claim that on the list of what counts as ethical excellence in humans there are certain dispositions, emotions and motives which make their possessors into people worthy of admiration. These so-called excellences have then been considered intrinsically valuable or instrumentally valuable. Suppose we do think that there are certain character traits that are of intrinsic value. This would definitively be in line with the backward-looking sense. But in that case we can now reverse an argument from earlier. That is, if we are ready to use this sense of moral progress about persons, what prevents me in the first place from applying it to entities like institutions and countries that I also think display intrinsic values? Again, as far as I can see, nothing. ${ }^{29}$

As I have already pointed out, it seems safe to say that progress is not mere change. Stan Godlovitch's distinction between two different kinds of processes which may shape our views of progress is helpful. The first sense which Godlovitch identifies is what he refers to as the "Teleological or culminative progress", according to which the progress involves a "change toward some specified end-state or goal". This end-state might be more or less explicit, but some such goal is assumed when we have Teleological progress in mind. This kind of progress is then distinguished from what Godlovitch refers to as Ameliorative progress, which he describes as "gainful change" (ibid. p. 275).

Godlovitch seems to think that the teleological sense is descriptive; it does not involve any proper evaluative notion. Godlovitch maintains that moral progress does include this sense. It might not be clear to us what the end-state is, but we must acknowledge that there is some such end-state towards which something has progressed. I am not quite sure why he thinks this to be a necessary part of moral progress. Suppose a country changes its laws such that they do not any longer discriminate against Roma people. I might take that to be an example of a how a country has made moral progress. And it might also be natural to think that, in such a case, this country has taken a step towards the ideal state- how countries should be. Among other things, they should not involve discriminating laws. This might all be fine. Still, I do not see why I am thereby logically committed to endorse that there is such an ideal country. In fact, it seems perfectly possible that I could deny this and still say that the country has improved, and thus has made moral progress.

According to Godlovitch, "The teleological progress conveys nothing about the beneficial value of that change" (ibid. 275). This, he thinks, is conveyed by where some developmental stage approvingly supersedes another (loc.cit.). Now, the teleological sense is not what I had in mind with the back-or-forward sense of moral progress. They should rather be understood as two different ways of understanding this Ameliorative sense of moral progress.

Suppose we combine the ameliorative view with the backward sense. We then have a view that locates the improvement in something that has nothing to do with what effects this improvement will have on something else. The value can then basically be located in two places, which will give us three possibilities. First, it can accrue to one of the objects between which the progress relation is said to hold. Most likely it will be the positive relatum of the relation, say, the fact that country A now allows women to vote. Secondly, it might be the

\footnotetext{
${ }^{29}$ Notice that as I use the notion of intrinsic value to refer to a value that accrues to something in virtue of this something's internal features alone. As I have argued elsewhere (Rønnow-Rasmussen 2011), such a notion is in fact open to both objectivists and subjectivists (understood in a wide sense), so the above argument is in principle open to most contemporary views about value.
} 
value accruing to the very relation, the process of going from something bad to something good is something that we might find valuable for its own sake. Finally, it might be the value we ascribe to both the relatum and the process. In fact, there are various possibilities here that there is no room to go into here. ${ }^{30}$ Instead, I want to address an objection that I hinted at earlier and that I expect many will find lurking in the background.

Couldn't one argue that the person who expressed the backward-looking sense has a dilemma on his hands?

Consider the following claim. A state different from a preceding state is only valuable in so far it makes or at least contributes to making the world better. So either we say that the backward sense locates value in what makes the world better or we have to conclude that this sense is somehow an unreasonable sense of moral progress. But if we say the former, i.e., if we say that the reason why the state is valuable is that it makes the world better, then we have given up on the backward or culminative sense. This is, however, a non sequitur. Not all values are contributive values.

A contributive value is a value that we have a reason to promote because it makes something better, e.g., the world. If we believe that making people happy or at least causing them to have pleasant states of mind is valuable, then if we can accomplish this we ought to do so. The value accruing to pleasure is such that we should promote this. Or put it slightly differently. The appropriate response is to make more people have pleasure. But sometimes what is valuable is not what should be promoted. Something that is valuable might be such that we should not endeavour to realize it or desire that it obtains. Instead it is a state that we have a reason to favour in a quite different way. There are various other kinds of attitudes that it would be appropriate to have in cases when we are facing non-promotable values. Depending on the nature, then, of that which we deem to be valuable, the appropriate attitude would be, for instance, to respect, honour, gratify, etc.

For example, I might believe that while there was no reason to respect Charlie yesterday in virtue of some feature of his, today there is precisely a reason to respect him because he now exhibits this feature. But, and this should be stressed, this does not necessarily mean that the value that now accrues to Charlie in virtue of this very feature has made the world a better place or contributed to its betterness. In fact, it might even be that the world, for logical reasons, had to become worse in order for Charlie to acquire this value, the response to which then is not one of promoting.

Here is an example. Generally I believe people would believe that certain insights are at least indicators of moral progress, in particular but not necessarily if they lead to actions. Suppose I realize that my behaviour, my way of joking with a certain group of people has been based on prejudice. My alleged harmless jokes have made these people feel really bad. However, I have come to realise this but only after having witnessed on numerous occasions how bad I have made these people feel. Only then have I come to fully understand the effects of my jokes. It seems reasonable to say that I have in such case made some moral progress, but it also seems reasonable to say that if it is a condition that I come to this particular insight by bullying people it is not something that ought to be promoted. It is nevertheless an insight that should be favoured in some way. ${ }^{31}$

\footnotetext{
${ }^{30} \mathrm{I}$ have in mind the possibility that moral progress is a kind of organic unity. See F. Orsi (2015) who considers this possibility (p. 102).

${ }^{31}$ For a recent illuminating work on the perils of intellectual and moral decline; see Mulligan (2014).
} 
Acknowledgments I owe thanks for comments provided when a version of this paper was read to the audience at the conference, Moral Progress: Concept, Measurement, and Application (Vu University 2015) — excellently organized by Bert Musschenga and Gerben Meynen. I am also indebted to an anonymous referee, the members of the research seminar at Lund University, in particular to Henrik Andersson, Dan Egonsson, Fritz-Anton Fritzon, Frits Gåvertsson, Björn Petersson and Wlodek Rabinowicz for valuable discussion.

Open Access This article is distributed under the terms of the Creative Commons Attribution 4.0 International License (http://creativecommons.org/licenses/by/4.0/), which permits unrestricted use, distribution, and reproduction in any medium, provided you give appropriate credit to the original author(s) and the source, provide a link to the Creative Commons license, and indicate if changes were made.

\section{References}

Andersson H (2016) Parity and Comparability — a Concern Regarding Chang's Chaining Argument. Ethical Theory Moral Pract 19:245-253

Chang R (1997) Introduction. In Chang R (ed.) Introduction, Incommensurability, Incomparability, and Practical Reason Cambridge: Harvard University Press

Chang R (2002) Making comparisons count. Routledge, New York

Chang R (2015) Value Incomparability and Incommensurability. In: Hirose I, Olson J (eds) The Oxford Handbook of Value Theory. Oxford University Press, Oxford, pp. 205-225

Crockett MJ, Clarke L, Hauser MD, Robbins TW (2010) Serotonin selectively influences moral judgment and behavior through effects on harm aversion. PNAS 107(40):17433-17438

Fritzon, F-A (2014) Value Grounded on Attitudes-Subjectivism in Value Theory. Media-Tryck, (PhD thesis), http://lup.lub.lu.se/record/4584279

Godlovitch S (1998) Morally we roll along, (Optimistic reflections) on moral progress. J Appl Philos 15:271-286

Gustafsson JE, Espinoza N (2010) Conflicting Reasons in the Small-Improvement Argument. Philos Q 60(241):754-763

Macklin R (1977) Moral Progress. Ethics 87(4):370-382

Merton R K (1965) On the shoulders of giants. New York: Free Press.

Mulligan K (2014) Anatomies of Foolishness 1927-1937. Yearbook, Kungl. Vitterhetsakademien (KVHAA), Royal Swedish Academy of Letters, History and Antiquities: Stockholm, 109-129

Orsi F (2015) Value Theory. Bloomsbury, London

Ortega y Gasset J (1932) The revolt of the masses. W. W. Norton \& Company, New York

Pigden CR (1990) Geach on Good. Philos Q 40(159):129-154

Posner RA (1998) The Oliver Wendell Holmes Lectures: The Problematics of Moral and Legal Theory. Harv Law Rev 111(7):1637-1717

Posner R A (1999) The Problematics of Moral and Legal Theory. Harvard UP

Rabinowicz W (2008) Value Relations. Theoria 74(1):18-49

Rabinowicz W, Rønnow-Rasmussen T (2016) Value Taxonomy. In: Sander D, Brosch T (eds) Handbook of Value. Oxford University Press, Oxford, pp. 23-43

Rønnow-Rasmussen T (2003) Subjectivism and Objectivism; an Outline. In: Rabinowicz W, RønnowRasmussen T (eds) Patterns of Value; Essays on Formal Axiology and Value Analysis. Lund, Lund Philosophy Reports

Rønnow-Rasmussen T (2011) Personal Value. Oxford University Press, Oxford

Rønnow-Rasmussen T (2013) Good and Good for. The International Encyclopedia of Ethics

Rønnow-Rasmussen T (2015) “On-Conditionalism-On the Verge of a New Metaethical Theory”. Circulating ms

Sartwell C (2015) Can We Improve? New York Times, August 31

Schoenfield M (2014) Decision making in the face of parity. Philos Perspect 28:263-277

Swedish State (2014:8) Den mörka och okända historien - vitbok om övergrepp och kränkningar av romer under 1900-talet (White paper from the Swedish state) www.regeringen.se/ratts-dokument/departementsserienoch-promemorior/2014/03/ds-20148/

Westacott, E (2015) Value Relativism. The Internet Encyclopedia of Philosophy. www.iep.utm.edu

Zimmerman M J (2001) The Nature of Intrinsic Value, Rowman \& Littlefield 